\title{
Total synthesis of TMG-chitotriomycin based on an automated electrochemical assembly of a disaccharide building block
}

\author{
Yuta Isoda ${ }^{1}$, Norihiko Sasaki ${ }^{1}$, Kei Kitamura ${ }^{1}$, Shuji Takahashi ${ }^{1}$, Sujit Manmode ${ }^{1}$, \\ Naoko Takeda-Okuda ${ }^{2}$, Jun-ichi Tamura ${ }^{1,2,3}$, Toshiki Nokami ${ }^{*}{ }^{* 1,3}$ and Toshiyuki Itoh ${ }^{* 1,3}$
}

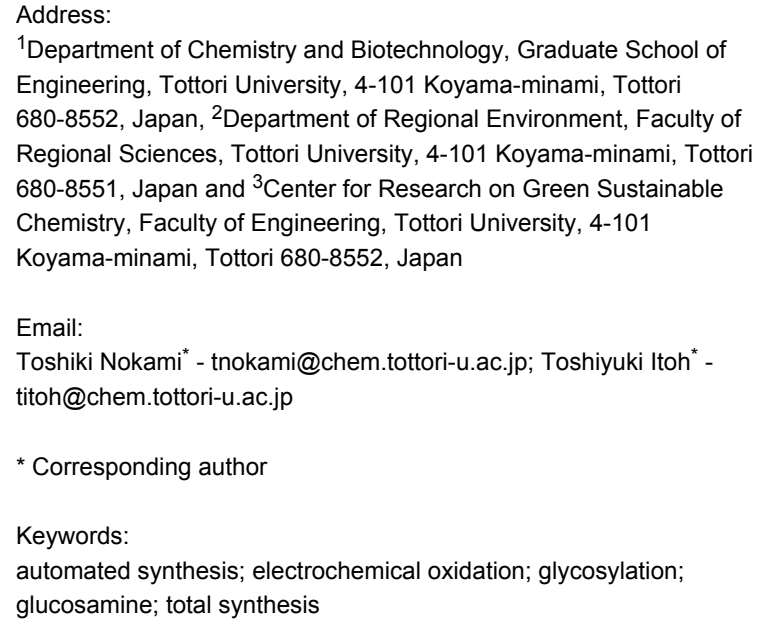

Beilstein J. Org. Chem. 2017, 13, 919-924. doi:10.3762/bjoc. 13.93

Received: 28 February 2017

Accepted: 04 May 2017

Published: 16 May 2017

This article is part of the Thematic Series "Biomolecular systems" and is dedicated to Professor Peter H. Seeberger on the occasion of his 50th birthday.

Guest Editor: P. H. Seeberger

(c) 2017 Isoda et al.; licensee Beilstein-Institut. License and terms: see end of document.

\begin{abstract}
The total synthesis of TMG-chitotriomycin using an automated electrochemical synthesizer for the assembly of carbohydrate building blocks is demonstrated. We have successfully prepared a precursor of TMG-chitotriomycin, which is a structurally-pure tetrasaccharide with typical protecting groups, through the methodology of automated electrochemical solution-phase synthesis developed by us. The synthesis of structurally well-defined TMG-chitotriomycin has been accomplished in 10-steps from a disaccharide building block.
\end{abstract}

\section{Introduction}

Degradation of chitin into oligoglucosamines and glucosamine is an important biological process and at least several enzymes such as chitinases and glucosaminidases are involved. Various types of inhibitors such as PUGNAc [1], nagastatin [2], NAGthiazoline (NGT) [3], and pochonicine [4], have already been developed. These compounds have exhibited strong inhibition

activity; however, they have a broad spectrum toward enzymes of various species including animals (Figure 1). N,N,NTrimethyl-D-glucosaminyl (TMG)-chitotriomycin (1) was isolated from Streptomyces anulatus by Kanzaki [5-7] and the first total synthesis was completed by $\mathrm{Yu}[8,9]$. Although the activity of TMG-chitotriomycin (1) was moderate, it selectively 


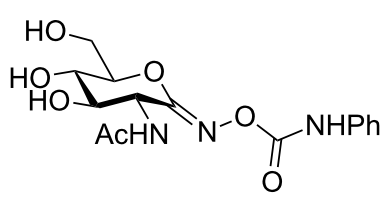

PUGNAC

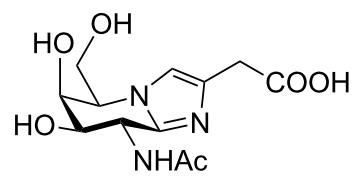

nagstatin

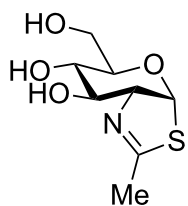

NAG-thiazoline (NGT)

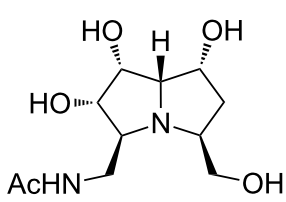

pochonicine

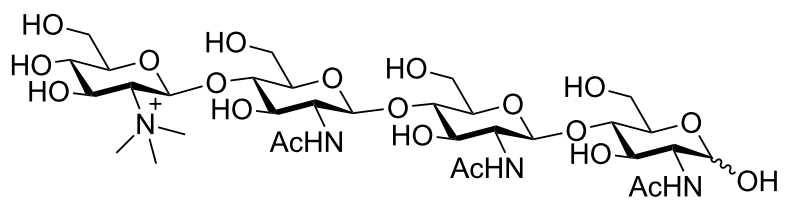

TMG-chitotriomycin (1)

Figure 1: Inhibitors of glucosaminidases.

inhibits glucosaminidases derived from insects and fungi. Therefore, TMG-chitotriomycin (1) has a potential as a lead compound for safe insecticides and pesticides. Recently, the total synthesis of TMG-chitotriomycin (1) initiated from building blocks that were prepared by the degradation of chitin has been reported by Beau [10]; however, practical synthetic methods to provide TMG-chitotriomycin (1) and its derivative in preparative scale are still highly desirable.

The automated synthesis of oligosaccharides is a powerful tool for the rapid synthesis of complex oligosaccharides [11-23]. We are interested in the automated synthesis of oligosaccharides based on the concept of "reaction integration" [24] and developed an automated synthesizer for the automated electrochemical assembly of carbohydrate building blocks [25]. During the course of our study, we have achieved the synthesis of a potential precursor of TMG-chitotriomycin (1); however, we obtained the tetrasaccharide as a mixture of $\alpha$ - and $\beta$-isomers in the terminal glycosidic linkage [26]. Here we report the total synthesis of TMG-chitotriomycin (1) as a single stereoisomer, which was prepared by automated electrochemical assembly started from a disaccharide building block.

\section{Results and Discussion}

To synthesize the potential precursor 7 of TMG-chitotriomycin (1) stereoselectively, we initiated our study by optimization of the reaction conditions of the first glycosylation using 2-deoxy2-azidothioglycoside $\mathbf{2}$ as a glycosyl donor. The azido group at the C2-position is a well-known substituent, which facilitates the formation of an $\alpha$-glycosidic linkage selectively due to the lack of neighboring group participation [27]. 4-Fluorophenyl 3,4,6-tri- $O$-acetyl-2-deoxy-2-azido- $\beta$-D-thioglucoside (2a) afforded the corresponding disaccharide $\alpha$-isomer $\mathbf{5 a \alpha}$ exclusively by the reaction with building block $\mathbf{4}$ via the glycosyl triflate intermediate 3a (Scheme 1). On the other hand, 4-fluorophenyl 3,4,6-tri- $O$ - benzyl-2-deoxy-2-azido- $\beta$-Dthioglucoside (2b) gave the disaccharide $\beta$-isomer $\mathbf{5 b} \boldsymbol{\beta}$ as the major product. Although the disaccharide $\alpha$ - and $\beta$-isomers of $5 \mathbf{b}(\mathbf{5 b \alpha} / \mathbf{5 b} \boldsymbol{b})$ have the same retention factor $\left(R_{\mathrm{f}}\right)$ in thin-layer chromatography (TLC, $R_{\mathrm{f}}=0.40$, hexane/EtOAc 5:2 as an

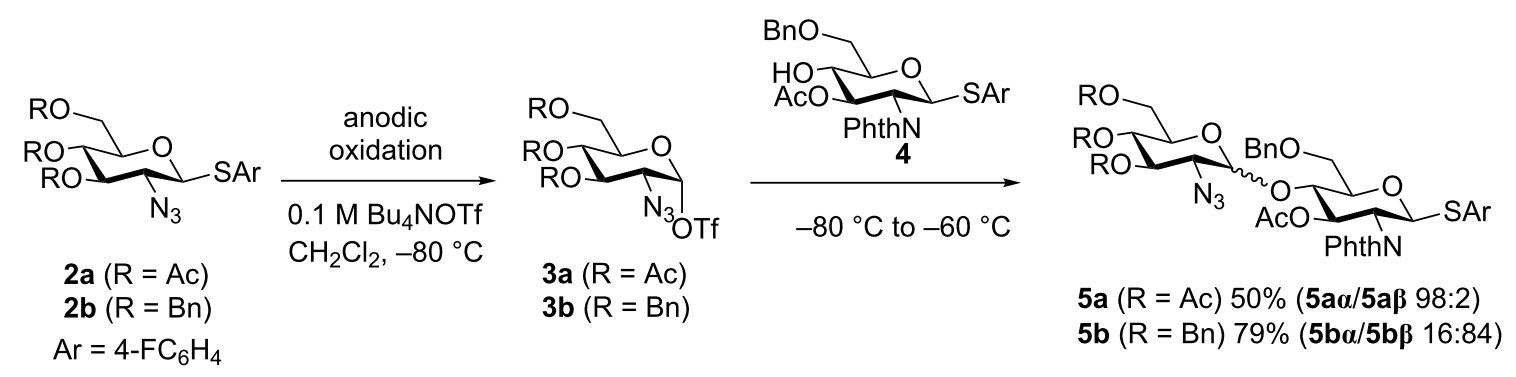


eluent), the pure $\beta$-disaccharide isomer $\mathbf{5 b} \boldsymbol{\beta}$ was obtained as colorless crystals after careful separation by silica gel chromatography.

It is still not clear why the disaccharide $\beta$-isomer $\mathbf{5 b} \boldsymbol{\beta}$ was obtained as a major product from glycosyl triflate 3 . We now assume that the difference in the reactivity of the $\alpha$ - and the $\beta$-glycosyl triflate intermediates 3 might determine the observed selectivity (Figure 2). We previously established that glycosyl triflate 3a was derived from thioglycoside $\mathbf{2 a}$ by an NMR study under low-temperature conditions, in which the glycosyl triflate $\alpha$-isomer $\mathbf{3 a} \boldsymbol{\alpha}$ was confirmed as an exclusive chemical species $[28,29]$. Taking the stability of the glycosyl triflate $\alpha$-isomer $\mathbf{3 a \alpha}$ into consideration, we propose a reaction mechanism involving $\alpha / \beta$ isomerization of glycosyl triflate 3a as shown in Figure 2. The more reactive $\beta$-isomer $\mathbf{3 a} \mathbf{\beta}$ might give the disaccharide $\alpha$-isomer $\mathbf{5 a} \boldsymbol{a}$ exclusively if there is an equilibrium between the $\alpha$-isomer and the $\beta$-isomer of $\mathbf{3 a}$. To the contrary, glycosyl triflate $\mathbf{3 b}$, derived from thioglycoside $\mathbf{2 b}$, might be more reactive and affords the $\beta$-product $\mathbf{5 b} \boldsymbol{\beta}$ before isomerization from the $\alpha$-isomer $\mathbf{3 b \alpha}$ to the $\beta$-isomer 3b及. In this case, glycosylation via $\mathbf{3 b a}$ becomes the major pathway [30]. Although it is hard to exclude another reaction mechanism involving oxocarbenium ions as reactive intermediates, the commonly accepted reactivity difference between $\alpha$ and $\beta$-isomers of glycosyl triflate 3 seems to explain the observed selectivity well.

Next, we attempted to synthesize the potential precursor 7 of TMG-chitotriomycin (1) using disaccharide $\mathbf{5 b} \boldsymbol{\beta}$ as a building block as illustrated in Figure 3. The automated electrochemical assembly of building blocks was initiated by the anodic oxidation of $\mathbf{5 b} \boldsymbol{\beta}$ and the subsequent coupling with thioglycoside $\mathbf{4}$ afforded the corresponding trisaccharide $\mathbf{6}$ as an intermediate after the 1 st cycle. The same process was repeated automatically in the 2 nd cycle and target tetrasaccharide 7 was obtained in $41 \%$ yield after purification by preparative gel permeation chromatography (GPC).

Deprotection and introduction of the TMG part to tetrasaccharide 7 were achieved by following the procedure reported by $\mathrm{Yu}$ and co-workers (Figure 4) [8]. Phthaloyl groups and acetyl groups of 7 are removed by the reaction with ethylenediamine followed by applying the conventional acetylation protocol with acetic anhydride $\left(\mathrm{Ac}_{2} \mathrm{O}\right)$ in the presence of $N, N$-dimethylaminopyridine (DMAP) to convert the amino groups into acetamide

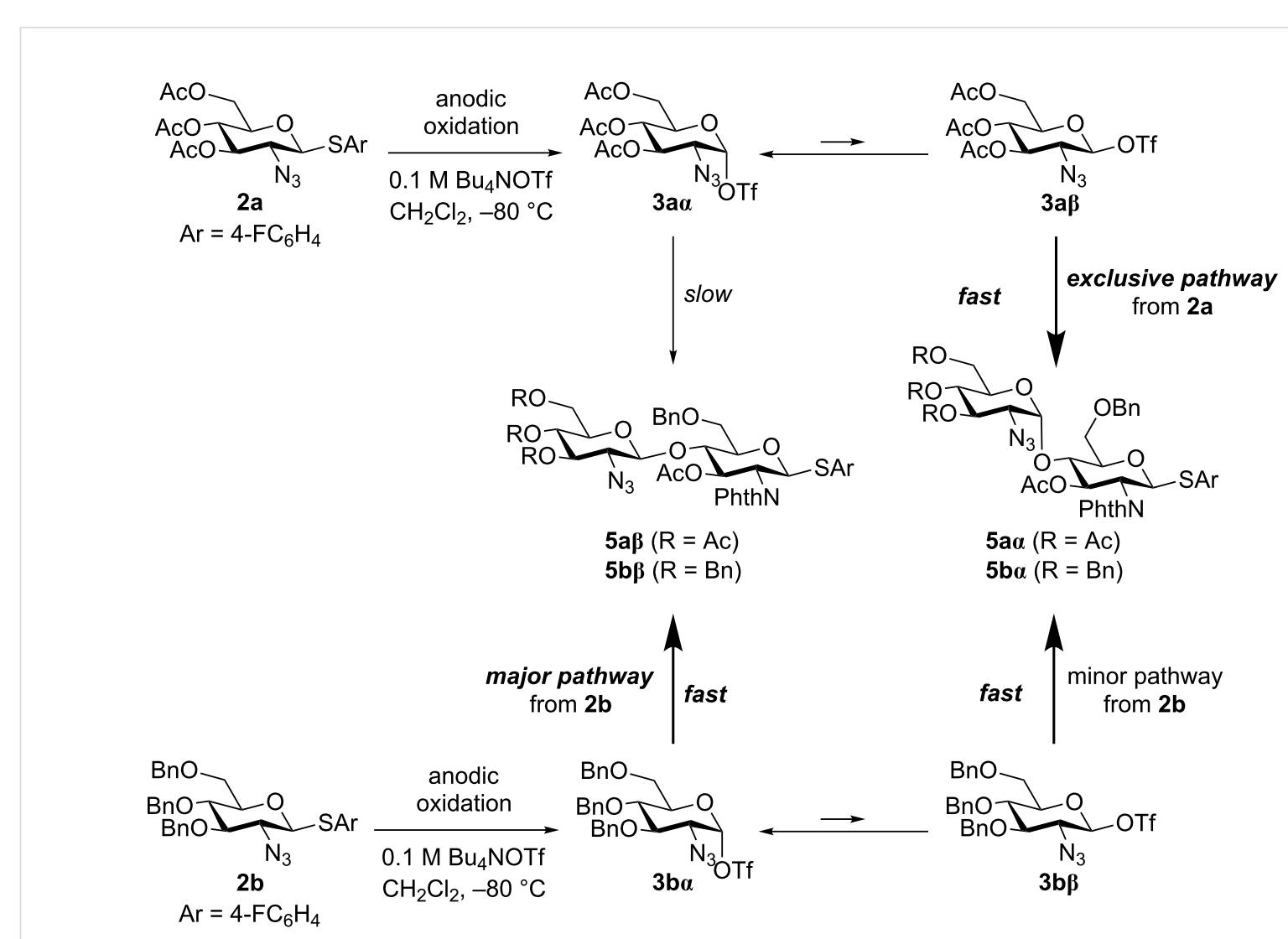



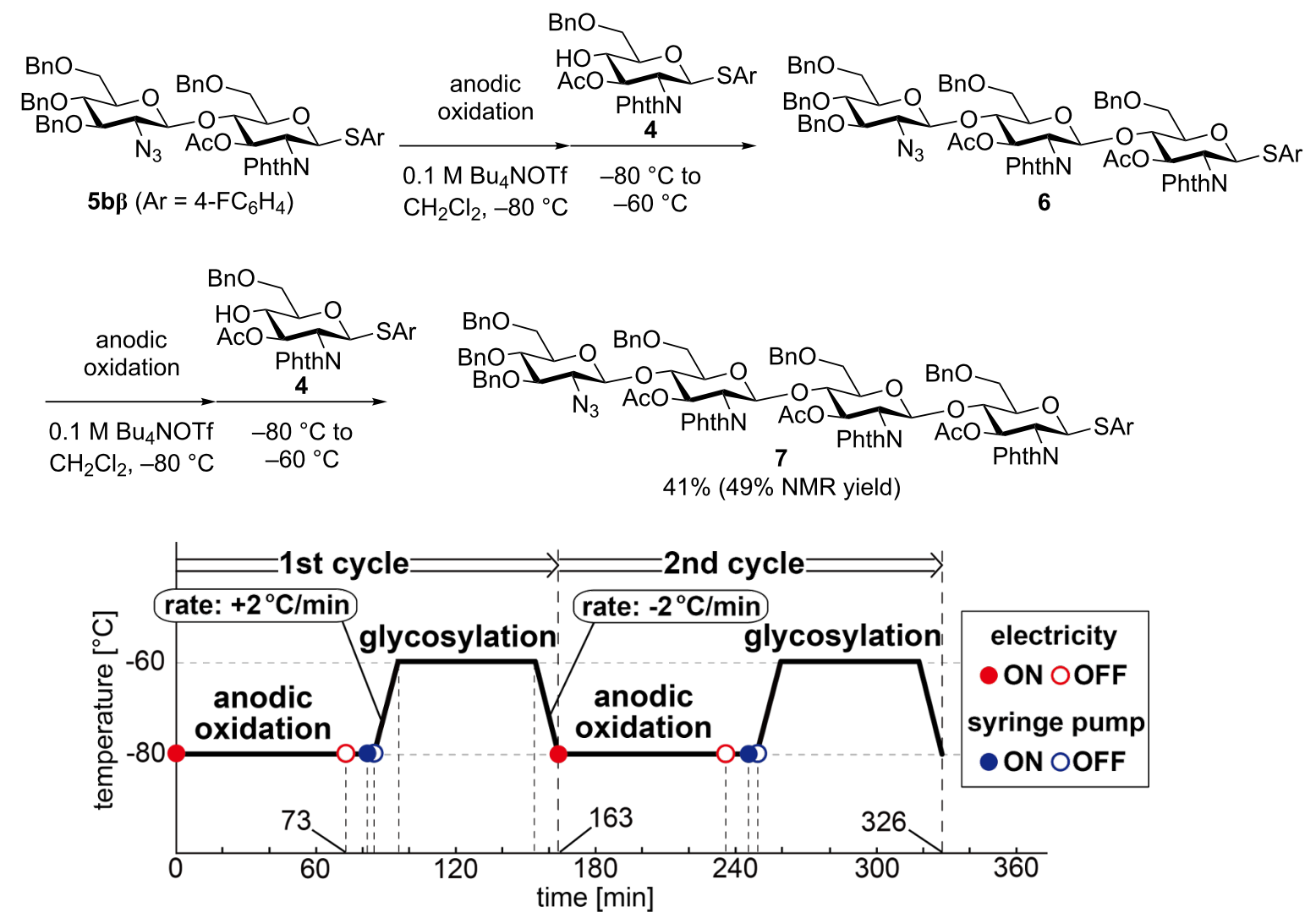

Figure 3: Synthesis of TMG-chitotriomycin precursor 7.
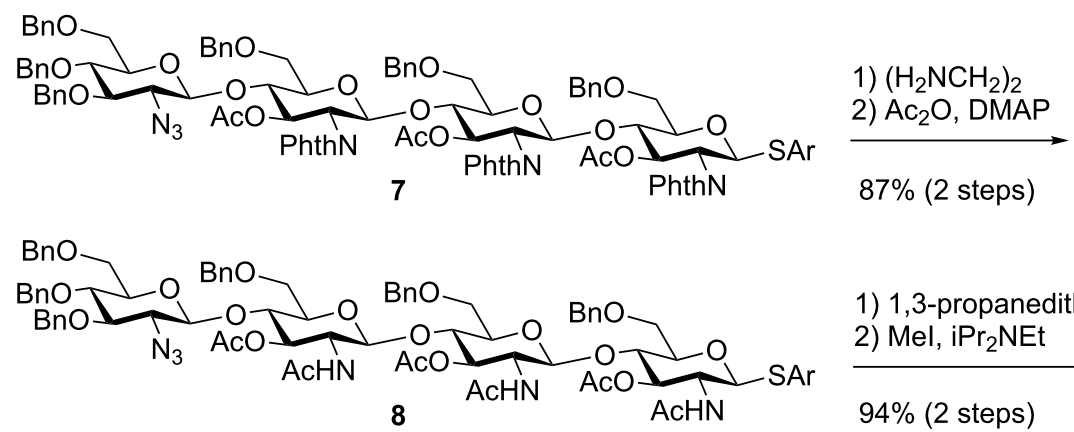

1) 1,3-propanedithiol 2) $\mathrm{Mel}, \mathrm{iPr}_{2} \mathrm{NEt}$

$94 \%$ (2 steps)

$\mathrm{BnO}$

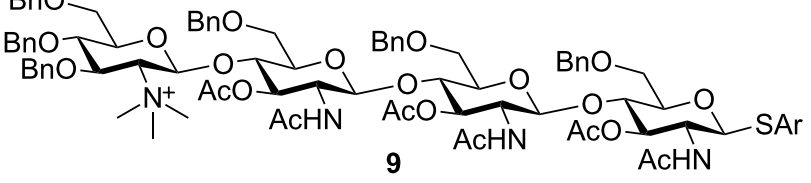

1) $\mathrm{K}_{2} \mathrm{CO}_{3}$

2) $\mathrm{H}_{2}, \mathrm{Pd}(\mathrm{OH})_{2} / \mathrm{C}$

$62 \%$ (2 steps)

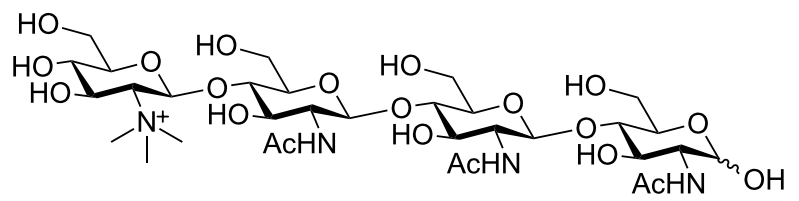

TMG-chitotriomycin (1)

Figure 4: Synthess of TMG-chitotriomycin (1). 
groups and to protect the hydroxy groups as acetyl groups. The 2-azido group of tetrasaccharide $\mathbf{8}$ was then reduced to a 2-amino group with 1,3-propanedithiol. Thus-obtained tetrasaccharide was treated with iodomethane (MeI) and $N, N$-diisopropylethylamine $\left(\mathrm{iPr}_{2} \mathrm{NEt}\right)$ to prepare the TMG part of tetrasaccharide 9. Deprotection of acetyl groups at the 3-O-positions and the subsequent global deprotection of the benzyl groups and the anomeric thioaryl group of the tetrasaccharide by hydrogenation with hydrogen gas in the presence of a palladium catalyst afforded TMG-chitotriomycin (1) in $21 \%$ yield (10 steps from disaccharide $\mathbf{5 b} \boldsymbol{\beta}$ ) [31].

\section{Conclusion}

In conclusion, we have achieved the stereoselective synthesis of TMG-chitotriomycin (1) based on the automated electrochemical assembly of disaccharide and monosaccharide building blocks. Thus-obtained structurally well-defined tetrasaccharide gave TMG-chitotriomycin after manipulations of the amino groups and global deprotection. Further investigations to improve the $\beta$-selectivity in the disaccharide synthesis and a large scale synthesis are in progress in our laboratory.

\section{Experimental}

\section{General}

${ }^{1} \mathrm{H}$ and ${ }^{13} \mathrm{C}$ NMR spectra were recorded in $\mathrm{CDCl}_{3}$ on a Bruker AVANCE II 600 spectrometer $\left({ }^{1} \mathrm{H} 600 \mathrm{MHz},{ }^{13} \mathrm{C} 150 \mathrm{MHz}\right)$ with $\mathrm{Me}_{4} \mathrm{Si}$ as an internal standard unless otherwise noted. Mass spectra were obtained on a Thermo Scientific Exactive mass spectrometer. Thin-layer chromatography (TLC) was carried out by using Merck precoated silica gel F254 plates (thickness $0.25 \mathrm{~mm}$ ). Flash chromatography was carried out on a column of silica gel (Kanto Chem. Co., Silica Gel N, spherical, neutral). Gel permeation chromatography (GPC) was carried out on a Japan Analytical Industry LC-918 equipped with JAIGEL-2H using $\mathrm{CHCl}_{3}$ as eluent. All reactions were performed under an Ar atmosphere unless otherwise noted.

\section{Materials}

All materials including solvents were purchased and used without further purification. Carbohydrate building blocks 2a, 2b, and 4 were prepared according to an previous report [11].

\section{Automated synthesis of TMG-chitotriomycin precursor 7}

The H-type glass cell equipped with glass filter was dried under vacuum and then filled with argon gas. Disaccharide building block $\mathbf{5 b} \boldsymbol{\beta}$ (0.43 mmol, $436 \mathrm{mg}$ ) was placed in the anodic chamber together with $\mathrm{Bu}_{4} \mathrm{NOTf}(1.7 \mathrm{mmol}, 672 \mathrm{mg})$ and anhydrous dichloromethane $(16 \mathrm{~mL})$. In the cathodic chamber $\mathrm{Bu}_{4} \operatorname{NOTf}(1.7 \mathrm{mmol}, 676 \mathrm{mg}$ ) and anhydrous dichloromethane $(16 \mathrm{~mL})$ was placed with TfOH $(1 \mathrm{mmol}, 90 \mu \mathrm{L})$. The auto- mated synthesis was started immediately after the cooling bath temperature reached $-80^{\circ} \mathrm{C}$. The anodic oxidation $(1.05 \mathrm{~F} / \mathrm{mol}$, $10 \mathrm{~mA}$ ) takes 73 minutes and then a dichloromethane solution containing building block $4(0.43 \mathrm{mmol}, 1.0 \mathrm{~mL})$ was added by a syringe pump. After addition of the building block, the temperature of the cooling bath was raised to $-60{ }^{\circ} \mathrm{C}$ and the reaction mixture was stirred for $1 \mathrm{~h}$ at this temperature. Then the temperature of the cooling bath was cooled again at $-80{ }^{\circ} \mathrm{C}$ to start the 2 nd cycle. It takes about 326 minutes (ca. 5 h $30 \mathrm{~min}$ ) to complete the automated assembly of building blocks. The reaction was quenched with $\mathrm{Et}_{3} \mathrm{~N}(0.5 \mathrm{~mL})$ at $-80{ }^{\circ} \mathrm{C}$ and the cell was taken from the cooling bath. The reaction mixture of the anodic chamber was evaporated and the thus-obtained crude product was purified by silica gel chromatography (hexane/ EtOAc 1:1 as eluent). The precursor 7 was obtained in $49 \%$ yield $(411 \mathrm{mg})$ together with building block 4 as an impurity. Further purification by $\mathrm{GPC}\left(\mathrm{CHCl}_{3}\right.$ as eluent) afforded 7 in $41 \%$ yield ( $328 \mathrm{mg}, 0.178 \mathrm{mmol}$ ).

\section{Supporting Information}

\section{Supporting Information File 1}

Experimental details of electrochemical glycosylation, global deprotection, and NMR spectra of unknown compounds.

[http://www.beilstein-journals.org/bjoc/content/ supplementary/1860-5397-13-93-S1.pdf]

\section{Acknowledgements}

This work is financially supported by JSPS Grant-in-Aid for Scientific Research on Innovative Areas (No. 2707) "Middle Molecular Strategy" Grant Number JP15H05844. T. N. thanks discretionary funds of the president of Tottori University.

\section{References}

1. Horsch, M.; Hoesch, L.; Vasella, A.; Rast, D. M. Eur. J. Biochem. 1991, 197, 815-818. doi:10.1111/j.1432-1033.1991.tb15976.x

2. Aoyagi, T.; Suda, H.; Uotani, K.; Kojima, F.; Aoyama, T.; Horiguchi, K.; Hamada, M.; Takeuchi, T. J. Antibiot. 1992, 45, 1404-1408. doi:10.7164/antibiotics.45.1404

3. Knapp, S.; Vocadlo, D.; Gao, Z.; Kirk, B.; Lou, J.; Withers, S. G. J. Am. Chem. Soc. 1996, 118, 6804-6805. doi:10.1021/ja960826u

4. Usuki, H.; Toyo-oka, M.; Kanzaki, H.; Okuda, T.; Nitoda, T. Bioorg. Med. Chem. 2009, 17, 7248-7253. doi:10.1016/j.bmc.2009.08.052

5. Usuki, H.; Nitoda, T.; Ichikawa, M.; Yamaji, N.; Iwashita, T.; Komura, H.; Kanzaki, H. J. Am. Chem. Soc. 2008, 130, 4146-4152. doi:10.1021/ja077641f

6. Usuki, H.; Yamamoto, Y.; Kumagai, Y.; Nitoda, T.; Kanzaki, H.; Hatanaka, T. Org. Biomol. Chem. 2011, 9, 2943-2951. doi:10.1039/C0OB01090A 
7. Shiota, H.; Kanzaki, H.; Hatanaka, T.; Nitoda, T. Carbohydr. Res. 2013, 375, 29-34. doi:10.1016/j.carres.2013.04.024

8. Yang, Y.; Li, Y.; Yu, B. J. Am. Chem. Soc. 2009, 131, 12076-12077. doi:10.1021/ja9055245

9. Yang, Y.; Liu, T.; Yang, Y.; Wu, Q.; Yang, Q.; Yu, B. ChemBioChem 2011, 12, 457-467. doi:10.1002/cbic.201000561

10. Despras, G.; Alix, A.; Urban, D.; Vauzeilles, B.; Beau, J.-M. Angew. Chem., Int. Ed. 2014, 53, 11912-11916. doi:10.1002/anie.201406802

11. Plante, O. J.; Palmacci, E. R.; Seeberger, P. H. Science 2001, 291, 1523-1527. doi:10.1126/science.1057324

12. Werz, D. B.; Castagner, B.; Seeberger, P. H. J. Am. Chem. Soc. 2007, 129, 2770-2771. doi:10.1021/ja069218x

13. Walvoort, M. T. C.; Volbeda, A. G.; Reintjens, N. R. M.; van den Elst, H.; Plante, O. J.; Overkleeft, H. S.; van der Marel, G. A.; Codée, J. D. C. Org. Lett. 2012, 14, 3776-3779. doi:10.1021/ol301666n

14. Kröck, L.; Esposito, D.; Castagner, B.; Wang, C.-C.; Bindschädler, P.; Seeberger, P. H. Chem. Sci. 2012, 3, 1617-1622. doi:10.1039/C2SC00940D

15. Ganesh, N. V.; Fujikawa, K.; Tan, Y. H.; Stine, K. J.; Demchenko, A. V. Org. Lett. 2012, 14, 3036-3039. doi:10.1021/ol301105y

16. Calin, O.; Eller, S.; Seeberger, P. H. Angew. Chem., Int. Ed. 2013, 52, 5862-5865. doi:10.1002/anie.201210176

17. Eller, S.; Collot, M.; Yin, J.; Hahm, H. S.; Seeberger, P. H. Angew. Chem., Int. Ed. 2013, 52, 5858-5861. doi:10.1002/anie.201210132

18. Tang, S.-L.; Pohl, N. L. B. Org. Lett. 2015, 17, 2642-2645. doi:10.1021/acs.orglett.5b01013

19. Schmidt, D.; Schuhmacher, F.; Geissner, A.; Seeberger, P. H.; Pfrengle, F. Chem. - Eur. J. 2015, 21, 5709-5713. doi:10.1002/chem.201500065

20. Fair, R. J.; Hahm, H. S.; Seeberger, P. H. Chem. Commun. 2015, 51, 6183-6185. doi:10.1039/C5CC01368B

21. Pistorio, S. G.; Nigudkar, S. S.; Stine, K. J.; Demchenko, A. V. J. Org. Chem. 2016, 81, 8796-8805. doi:10.1021/acs.joc.6b01439

22. Hahm, H. S.; Hurevich, M.; Seeberger, P. H. Nat. Commun. 2016, 7, No. 12482. doi:10.1038/ncomms 12482

23. Hahm, H. S.; Broecker, F.; Kawasaki, F.; Mietzsch, M.; Heilbronn, R.; Fukuda, M.; Seeberger, P. H. Chem 2017, 2, 114-124. doi:10.1016/j.chempr.2016.12.004

24. Yoshida, J.-i.; Shimizu, A.; Ashikari, Y.; Morofuji, T.; Hayashi, R.; Nokami, T.; Nagaki, A. Bull. Chem. Soc. Jpn. 2015, 88, 763-775. doi:10.1246/bcsj.20150100

25. Nokami, T.; Hayashi, R.; Saigusa, Y.; Shimizu, A.; Liu, C.-Y.; Mong, K.-K. T.; Yoshida, J.-i. Org. Lett. 2013, 15, 4520-4523. doi:10.1021/ol402034g

26. Nokami, T.; Isoda, Y.; Sasaki, N.; Takaiso, A.; Hayase, S.; Itoh, T.; Hayashi, R.; Shimizu, A.; Yoshida, J.-i. Org. Lett. 2015, 17, 1525-1528. doi:10.1021/acs.orglett.5b00406

27. Baeschin, D. K.; Charperon, A. R.; Charbonneau, V.; Green, L. G.; Ley, S. V.; Lücking, U.; Walter, E. Angew. Chem., Int. Ed. 1998, 37, 3423-3428. doi:10.1002/(SICI)1521-3773(19981231)37:24<3423::AID-ANIE3423>3 .0.CO;2-I

28. Nokami, T.; Shibuya, A.; Tsuyama, H.; Suga, S.; Bowers, A. A.; Crich, D.; Yoshida, J.-i. J. Am. Chem. Soc. 2007, 129, 10922-10928. doi:10.1021/ja072440x

29. Nokami, T.; Shibuya, A.; Manabe, S.; Ito, Y.; Yoshida, J.-i. Chem. - Eur. J. 2009, 15, 2252-2255. doi:10.1002/chem.200802293
30. Glycosyl triflate 3ba was observable as a major product by low temperature NMR measurement. Nokami, T.; Shibuya, A.; Manabe, S.; Ito, Y.; Yoshida, J. unpublished results.

31. When the global deprotection with a palladium catalyst with hydrogen gas was performed in methanol, we detected the molecular ion peak of the corresponding methyl glycoside of TMG-chitotriomycin.

\section{License and Terms}

This is an Open Access article under the terms of the Creative Commons Attribution License

(http://creativecommons.org/licenses/by/4.0), which permits unrestricted use, distribution, and reproduction in any medium, provided the original work is properly cited.

The license is subject to the Beilstein Journal of Organic Chemistry terms and conditions: (http://www.beilstein-journals.org/bjoc)

The definitive version of this article is the electronic one which can be found at: doi:10.3762/bjoc. 13.93 